\title{
Breves apontamentos sobre as modalidades de prisão cautelar no sistema processual penal brasileiro
}

\author{
Fábio Martins Pereira ${ }^{1}$ \\ Fernanda Simões Viotto Pereira ${ }^{2}$
}

\section{Resumo}

Este trabalho tem por objetivo maior fazer uma exposição sintética sobre as espécies de prisão de natureza cautelar previstas no ordenamento jurídico processual penal pátrio. A prisão, como uma medida legitimamente aceita pelo Estado brasileiro, ao exercer o ius puniendi, merece ser enfocada com atenção, sob pena de se cometer erros irreparáveis no meio social. Analisando-a mais detidamente, ver-se-á uma diferenciação entre a prisão processual da prisão nãoprocessual. Não deixando também de se fazer a separação, dentro do gênero prisão processual, da prisão pena da prisão sem-pena. Esta se caracteriza por ser declarada com base em um juízo de culpabilidade, e ter cunho acautelatório. As diversas espécies da prisão sem-pena, ou cautelar, - que são: a prisão em flagrante, a prisão temporária, a prisão decorrente de sentença de pronúncia, a prisão preventiva, a prisão resultante de sentença condenatória recorrível e prisão preventiva stricto sensu -, têm como fundamento a Constituição Federal de 1988, que não titubeia ao dar a elas, expressamente, caráter excepcional.

Palavras-Chave: Prisão. Prisão Definitiva. Prisão sem Pena. Prisão Cautelar. Prisão em Flagrante. Prisão Temporária. Prisão decorrente da Sentença de Pronúncia. Prisão resultante de Sentença Condenatória Recorrível. Prisão Preventiva Stricto Sensu.

\section{Conceitos de prisão}

Tales Castelo Branco definiu a prisão como "qualquer restrição a liberdade individual, dentro de casa, ou de penitenciária, ou de dependências policiais, ou de quartel, ou de casa fechada destinada a punição ou a correção, ou, ainda, pela limitação da liberdade mediante algemas, ou ligações a pesos etc." ${ }^{3}$

1 Advogado em Londrina/Pr. Professor do Departamento de Direito Público da Universidade Estadual de Londrina e do Instituto Catuaí de Ensino Superior em Cambé/Pr. Especialista em Direito Empresarial pela Universidade Estadual de Londrina.

2 Advogada em Londrina/Pr. Especialista em Direito Civil e Processual Civil pela Universidade Estadual de Londrina.

3 BRANCO, Tales Castelo. Da Prisão em Flagrante. São Paulo: Saraiva, 1980. p. 04. 
Em sentido jurídico, a prisão nada mais é do que "a privação da liberdade de locomoção, ou seja, do direito de ir e vir, por motivo lícito ou por ordem legal”4

É a "privação de liberdade de locomoção determinada por ordem escrita da autoridade competente ou em caso de flagrante delito" ${ }^{5}$.

Para José Frederico Marques, a prisão consiste na "pena privativa de liberdade imposta ao delinqüente, cumprida, mediante clausura, em estabelecimento penal para este fim destinado" ${ }^{6}$

No mesmo sentido, Fernando da Costa Tourinho Filho afirma que "a prisão é a supressão da liberdade individual, mediante clausura. É a privação da liberdade de ir e vir"7

\section{Tipos de prisão}

São reconhecidas pelo ordenamento jurídico brasileiro várias espécies de prisão. $\mathrm{A}$ doutrina a classifica de diferentes modos, não havendo um consenso a respeito da matéria.

O sistema processual penal brasileiro faz distinção entre dois tipos de prisão, quais sejam, a prisão penal e a prisão sem pena.

Fernando da Costa Tourinho Filho faz a seguinte explanação sobre o tema:

Esse conceito abrange as duas espécies de prisão: a prisão como pena, ou prisãosanção, isto é, a decorrente de sentença penal condenatória, utilizada como meio de repressão aos crimes e contravenções, e a prisão sem o caráter de pena, também conhecida sob a denominação genérica de prisão sem pena. ${ }^{8}$

\subsection{Prisão penal ou definitiva}

Prisão penal é a prisão definitiva, fundada no cumprimento de uma sentença penal condenatória, transitada em julgado, oriunda de processo crime, norteado pelos princípios processuais penais.

Tem ela caráter verdadeiramente repressor, punitivo, sancionador.

MIRABETE, Júlio Fabbrini. Processo Penal. São Paulo: Atlas, 1991, p. 343.

CAPEZ, Fernando. Curso de Processo Penal. 2.ed. São Paulo: Saraiva, 1999. p.227.

MARQUES, José Frederico. Elementos de direito processual penal. v. IV. Rio de Janeiro: Forense, 1965. p. 21.

TOURINHO FILHO, Fernando da Costa. Processo Penal. v. III. 5. ed. São Paulo: Jalovi, 1979. p. 329.

TOURINHO FILHO, Fernando da Costa. Manual de Processo Penal. 5. ed. São Paulo: Atlas, 2003. p. 543. 
Para Fernando da Costa Tourinho Filho, a prisão penal "é o sofrimento imposto pelo Estado ao infrator, em execução de uma sentença penal, como retribuição ao mal praticado, a fim de reintegrar a ordem jurídica injuriada." ${ }^{9}$

É a prisão penal resultante de uma decisão penal condenatória, aparecendo no ordenamento jurídico brasileiro sob várias formas, segundo os ensinamentos de Júlio Fabbrini Mirabete ${ }^{10}$ : “a) pena de reclusão e pena de detenção no CP; b) prisão no art. 240 do CPPM e, finalmente, a prisão especialíssima dos jornalistas de que cuida o parágrafo único do art. 66 da Lei n. 5.255 de 9.2.1967".

Fernando da Costa Tourinho Filho, ainda menciona como modalidade de prisãopena a prisão simples, disciplinada na Lei das Contravenções Penais.

A prisão resultante de sentença condenatória transitada em julgado é imposta através de um processo criminal no qual, sob a égide de princípios constitucionalmente consagrados, são produzidas as provas necessárias para um julgamento justo e eficaz.

No curso da instrução criminal, devem ser observados os princípios constitucionais do devido processo legal, da presunção da inocência e do contraditório e ampla defesa, sob pena e nulidade do processo desde o início, por manifesto cerceamento de defesa.

O julgador, ao condenar o réu, deve fundamentar sua decisão, não podendo levar em conta meramente indícios, mas provas sérias e robustas produzidas no processo.

Neste diapasão, Eliezer Rosa ensina que

o indício, na eterna ironia das coisas é a prova predileta da vida contra os inocentes... Condenar ou absolver é o que há de mais fácil e simples, quando o julgador aposta com os indícios o destino do processo. Julgar só mediante indícios e com eles condenar, é o adultério da razão com o acaso, nos jardins de Júpiter. ${ }^{11}$

Ao final, se esgotadas todas as possibilidades de modificação do destino do processo, com as vias recursais devidamente ultrapassadas, o Estado deve, por sua vez, cumprir seu papel perante a sociedade, com a imposição da devida execução da pena por ele mesmo imposta.

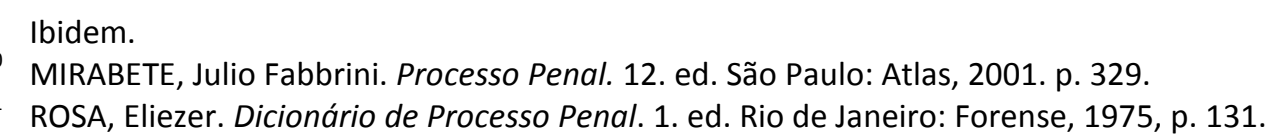




\subsection{Prisão sem pena}

Por prisão sem pena entende-se toda a forma de prisão provisória ou cautelar em sentido amplo, assim considerada em razão de recair sobre o indivíduo mesmo sem que haja sentença definitiva.

É revestida de caráter precário, por não ser definitiva, podendo ser decretada ou cassada a qualquer tempo, no curso da fase informativa ou da instrução processual.

Sua decretação não deflui de condenação e tem como finalidade resguardar o processo de conhecimento, pois, em alguns casos, se esta medida não for adotada, privando assim o indivíduo de sua liberdade mesmo sem uma sentença definitiva, quando esta for proferida, já não será possível a aplicação da lei penal.

Tem, pois, a natureza da prisão provisória, caráter de urgência e necessidade, que serve de instrumento para se atingir o fim esperado pelo processo de conhecimento, ou seja, a satisfação da pretensão.

Esta modalidade de prisão é de imensa variedade, não havendo uniformidade em sua classificação.

São exemplos de prisão sem pena: a) a prisão civil, prevista no Código Civil, no Código de Processo Civil e na Lei de Falências; b) prisão administrativa, prevista nos incisos I e Il do artigo 319 do Código de Processo Penal; c) prisão cautelar de natureza administrativa, pertinente à expulsão de estrangeiros e à extradição, prevista no Decreto-Lei $n^{\circ} 66.689$ de 11 de junho de 1970; d) prisão cautelar de natureza constitucional, admitida durante o estado de sítio; e, e) prisão cautelar de natureza processual penal, que é objeto do nosso estudo.

\section{Prisão cautelar de natureza processual penal}

Esta modalidade de prisão sem pena "nada mais é do que uma execução cautelar de natureza pessoal (em oposição à coerção processual de natureza real - como as buscas e apreensões, seqüestro, arresto, etc.) e que se justifica como medida imprescindível para assegurar o império da lei penal" ${ }^{12}$

Para Galeno Lacerda

12 TOURINHO FILHO, 1979. p. 336. 
a finalidade do processo cautelar consiste em obter segurança que torne útil e possível a prestação jurisdicional de conhecimento ou de execução. Nesta perspectiva, três necessidades podem surgir: a de garantir-se a prova, a de assegurar-se a execução quanto aos bens e a de outorgar-se desde logo a antecipação provisória e necessária ${ }^{13}$.

José Frederico Marques preleciona que

a prisão cautelar tem por objeto a garantia imediata da tutela de um bem jurídico para evitar as conseqüências do 'periculum in mora'. Prende-se para garantir a execução ulterior da pena, o cumprimento de futura sentença condenatória. Assentase ela num juízo de probabilidade; se não houver probabilidade de condenação, a providência cautelar é decretada a fim de que não se frustrem a sua execução e seu cumprimento. ${ }^{14}$

Nas lições de Paulo Rangel, a "prisão cautelar é uma espécie de medida cautelar, ou seja, é aquela que recai sobre o indivíduo, privando-o de sua liberdade de locomoção, mesmo sem sentença definitiva". ${ }^{15}$

Assegura ainda, o mesmo mestre que "a prisão cautelar tem como escopo resguardar o processo de conhecimento, pois, se não for adotada, privando o indivíduo de sua liberdade, mesmo sem sentença definitiva, quando esta for dada, já não será possível à aplicação da lei penal". ${ }^{16}$

Saliente-se que, a prisão provisória ou cautelar não pode ser vista como um reconhecimento antecipado da culpa, pois o juízo que se faz, ao decretá-la, é de periculosidade e não de culpabilidade.

Assim, nos dias atuais

não pode restar a menor dúvida de que a prisão em nosso direito tem a natureza acauteladora, destinada a assegurar a eficácia da decisão a ser prolatada afinal, bem como a possibilitar regular instrução probatória. Trata-se de tutelar os meios e os fins do processo de conhecimento e, por isso mesmo, de tutela da tutela ${ }^{17}$.

É aquela prisão anterior à condenação e que consiste em uma limitação mais ou menos intensa da liberdade física de uma pessoa, por uma finalidade processual penal.

13 LACERDA, Galeno. Comentários ao Código de Processo Civil. v. VIII. tomo II. Rio de Janeiro: Forense, 1998, p. 15.

14 MARQUES, 1965. p. 23.

15 RANGEL, Paulo. Direito Processual Penal. 3. ed. Rio de Janeiro: Lúmen Júris, 2000. p. 365.

16 Idem. p. 365.

17 JARDIM, Afrânio Silva. Direito Processual Penal. 5. ed. Rio de Janeiro: Forense, 1995, p. 360. 
Pode ser considerada como uma espécie de autodefesa do próprio ordenamento jurídico, ante o perigo de que seja burlado.

Historicamente, a prisão provisória, em uma visão ampla, é subordinada pela Constituição Federal, "de maneira inflexível e rigorosa, ao princípio da legalidade, tanto que, se o status libertatis do indivíduo for atingido por alguma coação ilegal, pode ele afastá-la mediante habeas corpus ${ }^{\prime 18}$.

Ao se verificar a decretação da medida cautelar - prisão provisória -, sem que se exponha, fundamentadamente, a justa causa para tal, estará se cometendo uma coação ilegal, segundo o artigo 648, I, do Código de Processo Penal.

Isso significa que o instituto da prisão cautelar - considerada a função processual que lhe é inerente - não pode ser utilizado com o objetivo de promover a antecipação satisfativa da pretensão punitiva do Estado, pois, se assim fosse lícito entender, subverterse-ia a finalidade da prisão preventiva, daí resultando grave comprometimento do princípio da liberdade.

Ao contrário, constitui instrumento destinado a atuar em benefício da atividade desenvolvida no processo penal.

Fernando Capez, em sua obra Curso de Processo Penal, ensina que esta modalidade de prisão, de natureza cautelar, é "destinada a assegurar o bom desempenho da investigação criminal, do processo penal ou da execução da pena, ou ainda a impedir que, solto, o sujeito continue praticando delitos. Depende do preenchimento do periculum in mora e do fumus boni iuris." ${ }^{19}$

O recolhimento provisório, denominado de prisão ad custodiam, tem como finalidade evitar as conseqüências do periculum in mora, sendo certo que, visa impedir a reiteração criminosa do delinqüente obstinado, e garantir a execução ulterior da pena e o cumprimento de futura sentença condenatória ${ }^{20}$.

Por conseguinte, verifica-se um juízo de probabilidade, ou seja, se houver probabilidade de condenação, e o interesse social assim requerer, a providência cautelar poderá ser decretada antecipadamente.

MARQUES, 1965. p. 27.

CAPEZ, 1999. p. 227-228.

20 PEDROSO, Fernando de Almeida. Processo Penal - O Direito de Defesa: Repercussão, Amplitude e Limites. 3. ed. São Paulo: Revista dos Tribunais, 2001. p. 92. 
Ressalte-se que a prisão provisória, em qualquer de suas modalidades, acima transcritas, a priori, não é compatível com o princípio da presunção da inocência estabelecido constitucionalmente pelo artigo 5으, inciso LVII.

O Ministro do Supremo Tribunal Federal, Celso de Mello, ao proferir sua decisão, ainda em sede de liminar, no Habeas Corpus n. 80.719-SP, que teve como Paciente Antônio Marcos Pimenta Neves, afirmou:

É inquestionável que a antecipação cautelar da prisão -qualquer que seja a modalidade autorizada pelo ordenamento positivo (prisão temporária, prisão preventiva ou prisão decorrente da sentença de pronúncia) - não se revela incompatível com o princípio constitucional da presunção de não-culpabilidade (RTJ 133/280 - RTJ 138/216 -RT 142/855 - RTJ 1421878 - RTJ 148/429 - HC 68.726-DF, Rei. Mm. NÉRI DA SILVEIRA).

Impõe-se advertir, no entanto, que a prisão cautelar - que não se confunde com a prisão penal (carcer ad poenam) - não objetiva infligir punição à pessoa que sofre a sua decretação. Não traduz, a prisão cautelar, em face da estrita finalidade a que se destina, qualquer idéia de sanção. Constitui, ao contrário, instrumento destinado a atuar "em beneficio da atividade desenvolvida no processo penal" (BASILEU GARCIA, "Comentários ao Código de Processo Penal”, vol. 11117, item n. 1, 1945, Forense).

Isso significa, portanto, que o instituto da prisão cautelar -considerada a função processual que lhe é inerente - não pode ser utilizado com o objetivo de promover a antecipação satisfativa da pretensão punitiva do Estado, pois, se assim fosse lícito entender, subverter-se-ia a finalidade da prisão preventiva, daí resultando grave comprometimento do princípio da liberdade.

Essa asserção permite compreender o rigor com que o Supremo Tribunal Federal tem examinado a utilização, por magistrados e Tribunais, do instituto da tutela cautelar penal, em ordem a impedir a subsistência dessa excepcional medida privativa da liberdade, quando inocorrente hipótese que possa justificá-la."(STF, HC n. 80.719-SP, Rel. Min. Celso de Mello, DJ. 23.03.2001).

\section{Uma breve distinção entre as espécies de prisão cautelar de natureza processual penal}

O Código de Processo Penal Brasileiro admite como espécies de prisão provisória: a prisão em flagrante; a prisão resultante de pronúncia; a prisão resultante debsentença condenatória que não faculta recurso em liberdade; a prisão temporária, e a prisãobpreventiva stricto sensu. 


\subsection{Prisão em flagrante}

Prisão em flagrante é a prisão provisória efetuada quando a infração penal está ocorrendo ou acaba de ocorrer, quando o delito está flamando, queimando. É o que se denomina de estado de flagrância.

É uma modalidade de prisão cautelar, sendo considerada como

a prisão de quem está cometendo o crime; acaba de cometê-lo; é perseguido, logo após, pela autoridade, pelo ofendido ou por qualquer pessoa, em situação que faça presumir ser autor da infração; é encontrado, logo depois, com instrumentos, armas, objetos ou papéis que façam presumir ser ele autor da infração ${ }^{21}$.

Para Guilherme de Souza Nucci, a prisão em flagrante "é a modalidade de prisão cautelar, de natureza administrativa, realizada no instante em que se desenvolve ou termina de se concluir a infração penal (crime ou contravenção penal)" ${ }^{22}$

É uma restrição a liberdade individual, de natureza administrativa, a qual, embora permitida pela Constituição, possui caráter excepcional, pois amplia o poder estatal de supremacia, em detrimento do direito de locomoção, sem as formalidades processuais de prévio controle jurisdicional. $^{23}$

São três os estados de flagrância que autorizam a prisão: a) o flagrante próprio, que ocorre quando o agente está cometendo a infração ou acaba de cometê-la; b) o flagrante impróprio ou quase-flagrante, que se dá quando o agente é perseguido logo após o ilícito, em situação que se faça presumir ser ele o autor da infração; e, c) o flagrante presumido, que é aquele em que o agente é encontrado logo depois, com instrumentos, armas, objetos ou papéis que façam presumir ser ele o autor da infração.

Nos crimes permanentes, ou seja, naqueles cuja ação se protrai no tempo, haverá flagrância enquanto não cessar a permanência.

Já, apesar das divergências doutrinárias, os crimes habituais, os quais exigem, para sua configuração, pluralidade de ações, não concebem a flagrância, eg.

21 TEIXEIRA, Renildo do Carmo. Da Prisão em Flagrante - Teoria, Prática e Jurisprudência. 2. ed. Leme-SP: Editora de Direito, 1998. p. 19.

$22 \mathrm{NUCCl}$, Guilherme de Souza. Código de Processo Penal Comentado. São Paulo: Revista dos Tribunais, 2002. p. 524

23 BRANCO, 1980. p. 43. 
quando a polícia efetua a prisão em flagrante, na hipótese de crime habitual, está surpreendendo o agente na prática de um só ato. $O$ auto de prisão vai apenas e tãosomente retratar aquele ato insulado. Não os demais. Ora, aquele ato isolado constitui um indiferente legal. O conjunto, a integralidade, não. ${ }^{24}$

\subsection{Prisão temporária}

A prisão temporária foi criada pela Lei n. 7.960/89.

Esta espécie de prisão cautelar de natureza processual penal só pode ser decretada por autoridade judiciária, mediante representação da autoridade policial ou a requerimento do Ministério Publico.

Fernando Capez define a prisão temporária como a "prisão cautelar de natureza processual destinada a possibilitar as investigações a respeito de crimes graves, durante o inquérito policial". ${ }^{25}$

O artigo 10 da Lei n. 7.960/89 é taxativo ao enumerar as situações em que pode ser decretada a prisão temporária, quais sejam: quando imprescindível para as investigações do Inquérito Policial; quando o indiciado não tiver residência fixa ou ainda não fornecer os elementos necessários para o esclarecimento de sua identidade; quando houver fundadas razões, de acordo com qualquer prova legalmente admitida, que aponte o indiciado como autor ou partícipe de homicídio doloso, seqüestro ou cárcere privado, roubo, extorsão, extorsão mediante seqüestro, estupro, atentado violento ao pudor, rapto violento, epidemia com resultado morte, envenenamento de água potável ou substância alimentícia ou medicinal qualificado pela morte, quadrilha ou bando, genocídio, tráfico de drogas e crimes contra o Sistema Financeiro.

\subsection{Prisão decorrente de sentença de pronúncia}

A prisão decorrente da sentença de pronúncia está prevista no Código de Processo Penal, no Capítulo destinado ao procedimento de crimes de competência do Tribunal do Júri, mais especificamente em seu artigo 408.

Estabelece o artigo em apreço que, se o Juiz se convencer da existência do crime e de indícios de que o réu seja seu autor, pronunciá-lo-á, dando os motivos de seu

\footnotetext{
24 TOURINHO FILHO, 1999. p. 384.

25 CAPEZ, 1999. p. 246.
} 
convencimento, proclamando, desta forma, ser admissível a acusação para que esta seja decidida pelo Plenário do Júri.

Em crime inafiançável, são efeitos da pronúncia: a) ser o réu submetido a julgamento pelo Tribunal do Júri; b) se houver motivo para a prisão preventiva, ser o réu recomendado na prisão em que se encontrar ou, se estiver solto, ser contra ele expedido mandado de prisão.

Hodiernamente, a sentença de Pronúncia não acarreta necessariamente a prisão do réu. Sendo esse primário e de bons antecedentes, poderá o Juiz deixar de decretarlhe a prisão ou revogá-la caso já esteja preso.

\subsection{Prisão decorrente de sentença condenatória recorrível}

O artigo 669, do Código de Processo Penal estabelece que, a sentença só será exeqüível depois de passar em julgado. Assim, tem-se, pois, que, em regra, a prisão penal só terá início quando transitada em julgado o comando judicial que impuser a pena privativa de liberdade.

Contudo, determina o artigo 594, do mesmo codex, que não poderá o réu apelar sem recolher-se a prisão, ou prestar fiança, salvo se ficar reconhecido na sentença que é primário e de bons antecedentes, ou se condenado por crime que se livre solto.

Importante ressaltar que a prisão de que trata o artigo em comento é prisão processual, sem pena, pois o réu ainda pode interpor recurso.

\subsection{Prisão Preventina Stricto Sensu}

A prisão preventiva também é uma das espécies de prisão provisória, posto que, como as demais, não é resultante de sentença penal condenatória, transitada em julgado.

Como já visto anteriormente, a privação cautelar da liberdade individual é qualificada pela nota da excepcionalidade. Assim, tem-se, pois, que, da mesma forma que as demais modalidades de prisão cautelar de natureza processual penal, a prisão preventiva só pode ser efetivada se o ato judicial que a formalize tenha fundamentação substancial.

Para Fernando da Costa Tourinho Filho, prisão preventiva "é aquela medida restritiva de liberdade determinada pelo Juiz, em qualquer fase do inquérito ou da instrução criminal, 
como medida cautelar, seja para garantir eventual execução da pena, seja para preservar a ordem pública, ou econômica, seja por conveniência da instrução criminal" ${ }^{26}$

Esta modalidade de prisão cautelar de natureza processual penal está prevista nos artigos 311 usque 316 do Código de Processo Penal, e só pode ser decretada unicamente pelo Juiz. Deve a prisão preventiva ser tida como o ponto central de toda e qualquer prisão cautelar de natureza processual penal, uma vez que, não havendo necessidade de ser ela decretada, as demais espécies não podem persistir.

Conforme os ensinamentos de Paulo Rangel :

no 'universo' da prisão cautelar de natureza processual, a prisão preventiva seria o sol e as demais prisões (em flagrante, em decorrência da decisão de pronúncia e em decorrência da sentença condenatória) seriam os planetas que o cercam e buscam nele sua fonte de luz, de energia, de sustento de vida. ${ }^{27}$

Só será admitida a decretação da prisão preventiva nos casos expressos no artigo 313 do Código de Processo Penal, ou seja, nos crimes dolosos: a) punidos com reclusão; b) punidos com detenção, quando o indiciado é vadio ou existe dúvida sobre a sua identidade; e, c) se o réu tiver sido condenado por outro crime doloso, com sentença transitada em julgado, salvo a hipótese descrita no parágrafo único do artigo 46 do Código Penal.

Entretanto, em se deparando o Juiz com uma das hipóteses acima mencionadas, ainda assim deverá analisar o caso concreto, uma vez que a prisão preventiva só é cabível em casos excepcionais.

A prisão preventiva pode ser decretada a qualquer momento, até mesmo antes do oferecimento da denúncia, e deverá sê-lo feito através de despacho fundamentado, devendo o Juiz demonstrar a existência dos fundamentos e dos requisitos desta modalidade de prisão cautelar.

Como toda providência cautelar, a prisão preventiva exige a existência de dois pressupostos para sua decretação: o fumus boni iuris e o periculum in mora.

O fumus boni iuris consiste na prova da materialidade dos fatos delituosos (da existência do crime) e na existência de indícios suficientes de autoria, sendo certo que, na falta da algum deles, não caberá a prisão preventiva.

26 TOURINHO FILHO, 1979. p. 570.
27 RANGEL, 2000. p. 390. 
Por sua vez, o periculum in mora consiste nas circunstâncias que autorizam a decretação da prisão preventiva, previstas no artigo 312, do Código de Processo Penal, quais sejam: garantia da ordem pública; conveniência da instrução criminal; asseguração de eventual pena a ser imposta.

Ordem pública é a necessidade de se manter a tranqüilidade social, a paz pública, que via de regra é abalado pela prática de um delito. Por conveniência da instrução criminal, entende-se como sendo o regular e equilibrado andamento do devido processo legal, em seu aspecto procedimental. Por fim, a asseguração de eventual pena a ser imposta é a garantia de que o eventual exercício do direito de punir do Estado será cumprido.

Basta que o Juiz fundamente a decretação da prisão preventiva em uma das circunstâncias acima nominadas, não havendo necessidade da presença de todas elas.

\begin{abstract}
A prisão preventiva é a prisão cautelar por excelência, bem como a mais utilizada hoje no processo penal brasileiro. Encontra-se disciplinada nos artigos 311 e seguintes do Código de processo Penal.

Todavia, é no artigo 312 que se encontram os requisitos necessários a sua decretação. Estes requisitos podem ser divididos em dois grupos que aqui denominaremos de concomitantes e alternativos. Para a decretação de toda e qualquer prisão preventiva devem estar presentes os dois requisitos concomitantes e ao menos um dos alternativos. São requisitos alternativos: a garantia da ordem pública, da ordem econômica, da aplicação da lei penal e a conveniência da instrução criminal. Enquanto são requisitos concomitantes: a prova da existência do crime (materialidade) e indícios suficientes de autoria. Alguns autores (5) ainda, numa clara comparação entre doutrina processual civil e penal, identificam os requisitos concomitantes como sendo o fummus boni iuris e os requisitos alternativos como o periculum in mora. ${ }^{28}$
\end{abstract}

Assim, diante do retro exposto, é forçoso concluir que a prisão preventiva só deve ser decretada se realmente necessária, sujeitando-se o Juiz a pressupostos e condições, evitando-se, desta forma, ao máximo, o comprometimento do direito de liberdade do indivíduo amparado pelo ordenamento jurídico.

É do relatório do Min. do STJ, Vicente Leal, no HC n. 23.879:

A prisão preventiva é uma medida extrema, foi concebida com cautela à luz do princípio constitucional da inocência presumida e deve basear-se em razões

28 CAVALHEIRO NETO, Augusto. A insuficiência da garantia da ordem pública como fundamento do decreto de prisão preventiva. Jus Navegandi. Teresina: 2.004. a. 8. n. 270. Disponível em: <http://jus2.uol.com.br/doutrina/imprimir.asp?id=5039>. Acesso em: 12 set. 2005. 
objetivas, que demonstrem a existência de motivos concretos suscetíveis de autorizar sua imposição. [...]

Segundo esclareceu o relator do habeas-corpus, ministro Vicente Leal, em inúmeros julgamentos tem-se afirmado que a prisão preventiva, por ser uma medida extrema que implica em sacrifício à liberdade individual, deve ser concebida com cautela.

'Principalmente agora, quando a nossa Carta Magna inscreveu o princípio da inocência presumida'.

O instituto da prisão preventiva subsiste no atual sistema constitucional, conforme o artigo 50 da Constituição Federal, e funda-se em razões de interesse social. Assim, continua o ministro Vicente Leal, “impõe-se sempre a sua decretação quando provada a existência do crime e constatados indícios suficientes da autoria e quando ocorrer a presença de qualquer dos pressupostos inscritos no artigo 312 do Código de Processo Penal, quais sejam, garantia da ordem pública; conveniência da instrução criminal e segurança na aplicação da lei penal". No entanto, o decreto de prisão preventiva deve ser adequadamente fundamentado, não bastando meras referências às circunstâncias do crime. 'È mister que o juiz demonstre com elementos condensados no processo a presença de, pelo menos, uma daquelas circunstâncias arroladas no artigo 312 , do $\mathrm{CPP}^{\prime 29}$

Os pressupostos da prisão preventiva estão previstos no artigo 312 do Código de Processo Penal, sendo eles: a prova da existência do crime e a existência de indícios suficientes de autoria.

Se ausente qualquer um dos pressupostos acima mencionados, não poderá ser decretada a prisão preventiva, sob pena de constrangimento ilegal, sanável por meio de "habeas-corpus".

\section{Considerações finais}

Este trabalho busca expor, de modo muito breve e pontual, as modalidades de prisão cautelar previstas no sistema jurídico processual penal pátrio. No processo penal, onde há um conflito entre o direito de punir estatal e o direito de liberdade do indivíduo e, por conseqüência, a dignidade humana está em jogo, a prisão é prevista tanto como medida de cautela, como espécie de pena. É necessária uma precisa distinção entre uma e outra a fim de se não desvirtuar, em especial, o caráter excepcional da primeira.

Como outrora exposto, há, basicamente, dois grandes grupos de prisão em nosso sistema. A que decorre de sentença penal condenatória transitada em julgado, conhecida como prisão pena, e a que não tem tal caráter de pena, chamada de prisão sem pena.

29 MACEDO, Idhelene. NOTÍCIAS DO SUPERIOR TRIBUNAL DE JUSTIÇA: Prisão preventiva deve se fundamentada em razões objetivas. Publ. em 12/12/2002. Disponível em <http://www.stj.gov.br/webstj/noticias/imprime_noticia.asp?seq_noticia=6998>. Acesso em: 12 set. 2005. 
A prisão pena decorre da decisão definitiva e irrecorrível prolatada ao final do processo criminal. Ela se destaca por ser repressiva, punitiva e sancionatória. Já a prisão sem pena diferencia-se da primeira por ser provisória em sentido lato e de cunho acautelatório. Ela só pode ser decretada excepcionalmente e em situações de extrema urgência e necessidade. O ordenamento jurídico prevê diversas espécies de prisão sem pena. Estas estão distribuídas nos ramos do Direito Processual Civil, do Direito Comercial, do Direito Administrativo e do Direito Processual Penal.

As prisões sem pena de natureza processual penal constituem o principal objeto de estudo deste trabalho. A exposição aqui feita sobre elas visa demonstrá-las comparativamente com as demais espécies de prisão legitimamente aceitas pelo ordenamento jurídico-constitucional. Não há, aqui, o fito de abordá-las de modo polêmico, mas apenas de fazer uma breve explanação acadêmica das diversas espécies de prisão; em especial as cautelares de natureza processual penal.

\section{Referências}

BRANCO, Tales Castelo. Da Prisão em Flagrante. São Paulo: Saraiva, 1980.

CAPEZ, Fernando. Curso de Processo Penal. 11. ed. São Paulo: Saraiva, 2004.

JARDIM, Afrânio Silva. Direito Processual Penal. 6. ed. Rio de Janeiro: Forense, 1998.

LACERDA, Galeno. Comentários ao Código de Processo Civil. v. VIII; tomo II. Rio de Janeiro: Forense, 1998.

MARQUES, José Frederico. Elementos de direito processual penal. Campinas: Bookseller, 1997. v. 9.

MIRABETE, Júlio Fabbrini. Processo Penal. São Paulo: Atlas, 1991.

Processo Penal. 12. ed. São Paulo: Atlas, 2001.

NUCCl, Guilherme de Souza. Código de Processo Penal Comentado. São Paulo: Revista dos Tribunais, 2002.

PEDROSO, Fernando de Almeida. Processo Penal - O Direito de Defesa: Repercussão, Amplitude e Limites. 3. ed. São Paulo: Revista dos Tribunais, 2001. 
RANGEL, Paulo. Direito Processual Penal. 3. ed. Rio de Janeiro: Lúmen Júris, 2000.

ROSA, Eliezer. Dicionário de Processo Penal. Rio de Janeiro: Forense, 1975.

TEIXEIRA, Renildo do Carmo. Da prisão em flagrante: teoria, prática e jurisprudência. 2. ed. Leme - SP: Editora de Direito, 1998.

TOURINHO FILHO, Fernando da Costa. Processo Penal. 5. ed. São Paulo: Jalovi, 1979. v. 3. . Manual de Processo Penal. 5. ed. São Paulo: Saraiva, 2003. 
